This document is the accepted manuscript version of the following article:

Stelzer, S., Brunner, A. J., Argüelles, A., Murphy, N., \& Pinter, G. (2012). Mode I delamination

fatigue crack growth in unidirectional fiber reinforced composites: Development of a standardized test procedure. Composites Science and Technology, 72(10), 1102-1107.

https://doi .org/10.1016/j.compscitech.2011.11.033

\title{
Mode I delamination fatigue crack growth in unidirectional fiber reinforced composites: Development of a standardized test procedure
}

\author{
S. Stelzer ${ }^{1}$, A.J. Brunner ${ }^{2}$, Antonio Argüelles ${ }^{3}$, Neal Murphy ${ }^{4}$, G. Pinter ${ }^{1,5}$ \\ ${ }^{1}$ Institute of Materials Science and Testing of Plastics, Montanuniversität Leoben, Franz- \\ Josef-Strasse 18, A-8700 Leoben, Austria, steffen.stelzer@unileoben.ac.at \\ 2 Empa, Swiss Federal Laboratories for Materials Science and Technology, \\ Überlandstrasse 129, CH-8600 Dübendorf, Switzerland \\ ${ }^{3}$ Department of Construction and Manufacturing Engineering, Universidad de Oviedo, \\ Campus de Viesques, Gijón 33203, Spain \\ ${ }^{4}$ School of Electrical, Electronic and Mechanical Engineering, UCD Engineering and \\ Materials Science Centre, University College Dublin, Belfield Dublin 4, Ireland \\ ${ }^{5}$ PCCL, Polymer Competence Center Leoben, Roseggerstrasse 12, A-8700 Leoben, \\ Austria
}

\section{Abstract}

Selected mode I fatigue data from five different types of fiber-reinforced, polymer-matrix composites tested in two round robins organized by the American Society for Testing and Materials subcommittee D30.06 and European Structural Integrity Society Technical Committee 4, respectively, are analyzed and discussed. The focus is on experimental scatter (inlaboratory and inter-laboratory) and on schemes for quantitative data analysis. It is shown that in spite of considerable scatter different composites can be distinguished and, under certain assumptions, a relative ranking be established. Further, effects from limited experimental measurement resolution are noted and implications for the test procedure and use of the test data in design of composite structures discussed. For comparative purposes, a rough ranking of different composites is feasible with test data generated within 24 hours per specimen in an industrial test environment. 
Keywords: A. Polymer-matrix composites (PMCs), B. delamination, B. fatigue, $B$. fracture, test development

\section{Introduction}

Characterization of delamination resistance of fiber-reinforced polymermatrix composites (FR-PMC) under quasi-static and cyclic fatigue loads is important for development of laminates with improved damage tolerance as well as for designing composite structures and, therefore, has been an active area of research for quite a while (see e.g., [1, 2] for a summary). While this has resulted in standardized test procedures or at least in standardization activities for quasi-static loading in different modes [3], this is not the case for cyclic fatigue yet. A procedure for mode I tensile opening cyclic fatigue testing of FR-PMC was evaluated in a first round robin test involving three laboratories and was shown to yield sufficiently reproducible results [4] and additional testing showed sufficient discrimination between selected, different types of FR-PMC [5]. Recently, additional round robin testing on mode I cyclic fatigue was performed, both within subcommittee D30.06 on interlaminar properties of composite materials of the American Society for Testing and Materials (ASTM) International and committee TC4 on fracture of polymers, composites and adhesives of the European Structural Integrity Society (ESIS). The present contribution evaluates selected results from these round robins and focuses on approaches for quantitative data analysis on one hand, and on experimental scatter and measurement resolution on the other. Implications for the test procedure under development will be discussed. 


\section{Experimental}

\subsection{Materials and specimens}

The materials used in the two round robin programmes are listed in Table 1 for ASTM D30.06 and in Table 2 for ESIS TC4. All tests were performed using double cantilever beam (DCB) specimens (according to ASTM D5528 or ISO 15024) with a total length of about $152 \mathrm{~mm}$ (ASTM) and of $145 \mathrm{~mm}$ (ESIS), a width of $20 \mathrm{~mm}$ and thicknesses as listed in Tables 1 and 2. Starter cracks were realised by using a PTFE film insert (about 5 $\mu \mathrm{m}$ for ASTM and about $20 \mu \mathrm{m}$ thick for ESIS) at the laminate mid-plane. Aluminium load-blocks (about $6 \mathrm{~mm}$ thick, $12.8 \mathrm{~mm}$ long and $20 \mathrm{~mm}$ wide, with a pin-hole with a diameter around $3.8 \mathrm{~mm}$ located towards the crack tip for ASTM, and $10 \mathrm{~mm}$ thick, $15 \mathrm{~mm}$ long and $20 \mathrm{~mm}$ wide with centered pin-hole with a diameter of $4 \mathrm{~mm}$ for ESIS) were mounted for load introduction.

\subsection{Procedure}

The ASTM test procedure first asked for drying the specimens according to ASTM D5229/D5229M and then storing them in a desiccator before testing under standard laboratory conditions of $(23 \pm 3)^{\circ} \mathrm{C}$ and $(50 \pm 10) \%$ relative humidity. The mode I fatigue test shall be performed without precracking at $10 \mathrm{~Hz}$ (if possible); at laboratory $\mathrm{B}$ tests were run with $3 \mathrm{~Hz}$ due to large displacements and with a R-ratio of 0.1 . Testing shall be continued until a delamination rate below $10^{-6} \mathrm{~mm} /$ cycle is reached in order to determine a threshold value. For determining the maximum cyclic displacement $\delta_{\max }$, a series of quasi-static tests shall be performed on a separate set of nominally identical specimens up to a delamination length 
of $75 \mathrm{~mm}$ beyond the initial crack tip. The quasi-static results shall be used to calculate $\delta_{\max }$ from the following relation (1):

$$
\begin{gathered}
\frac{\delta_{\text {max }}^{2}}{\left[\delta_{c r}\right]_{a v}^{2}}=\frac{G_{\text {Im } a x}}{G_{I c}}=0.8 \\
\text {, i.e., } \delta_{\max }=\sqrt{0.8\left[\delta_{c r}\right]_{a v}^{2}}
\end{gathered}
$$

where $G_{l c}$ is the critical strain energy release rate, $\left[\delta_{c r}\right]^{2}$ av is the average of the squared critical displacement values at $\mathrm{G}_{\mathrm{IC}}$ from the quasi-static tests and $\mathrm{G}_{\max }$ is the maximum cyclic strain energy release rate. Effectively, at laboratory $\mathrm{B}$, a factor of 0.8 proved to be too low to get the delamination propagation started from the initial crack within a sufficiently low number of cycles and a factor around 1.0 was used for most tests. The quasi-static data are summarized in Table 3 . One laboratory also tested additional specimens for delamination growth onset according to ASTM D6115 based on developments reported in [6].

The ESIS procedure specified that in order to start the measurements at high crack growth rates just below $G_{I C}$ a quasi-static mode I test for precracking was done as a $\mathrm{G}_{\mathrm{IC}}$-test at a cross-head speed between 1 and 5 $\mathrm{mm} / \mathrm{min}$. The displacement value at which pre-cracking was stopped was then taken as the $\delta_{\max }$ value for fatigue loading. The cyclic test was started and continued until a crack growth rate of about $10^{-6} \mathrm{~mm} /$ cycle was reached. An R-ratio of 0.1 was used in all the measurements and the tests were done under displacement control. Fatigue loading could be stopped to perform visual observation of delamination lengths with a travelling microscope. In order to avoid errors during the calculation of the results a spreadsheet macro file was created which was used by all the participants 


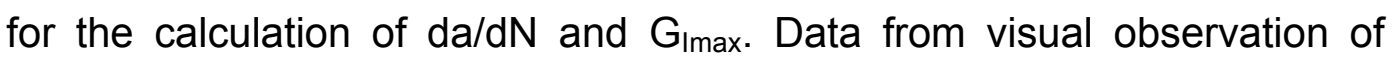
delamination propagation and from recorded machine compliance can be used to evaluate $\mathrm{G}_{\max }$ and the corresponding delamination rate da/dN. $\mathrm{G}_{\text {Imax }}$ is evaluated using simple beam theory, corrected beam theory and modified compliance calibration and the da/dN-values are calculated in a secant (point-wise) approximation or with a seven point polynomial fit (according to ASTM D647). The number of machine compliance data points can be reduced by specifying a minimum delamination length increment between subsequent data points in the data presentation graphs (typically $50 \mu \mathrm{m}$ was used). The same spreadsheet was used to analyze the ASTM round robin data from laboratory B. A typical set-up for mode I fatigue testing (laboratory B) is shown in Figure 1.

\section{Results and Discussion}

\subsection{ASTM Round Robin}

Only data from laboratory $B$ are available for the analysis and hence, no information on inter-laboratory scatter can be derived. On the other hand, as shown in Figure 2, the in-laboratory scatter of the data from visually recorded delamination lengths using a travelling microscope is such that it is somewhat difficult to even distinguish trends among the three laminates. This is different from the data presented in [5] where various carbon- and glass FR-PMC could easily be distinguished. It has to be noted that $\mathrm{G}_{\max }$ values are determined from the modified compliance calibration method (MCC, see [7]). As a second step in the analysis, the same data are plotted using delamination lengths calculated from recorded machine compliance data (machine load and displacement, respectively) [4] instead of visually determined delamination lengths (Figure 3). Since machine 
data have been recorded every 500 cycles, the number of data points is reduced by requiring a minimum delamination length increment of $50 \mu \mathrm{m}$ between individual data points in the spreadsheet used for data analysis. A $50 \mu \mathrm{m}$ delamination length increment roughly corresponds to the resolution of the visual delamination length measurement obtained with the microscope at laboratory B. This allows distinguishing differences in slope of the Paris plots for each group of laminate. In a next step, the data points for each specimen are replaced by a power law fit, $\frac{d a}{d N}=A \cdot G_{I \max }{ }^{m}$, which yields a quantitative result, namely the exponent $\mathrm{m}$, which represents the slope of the linear regime in the double logarithmic diagram. It has to be noted that these fits include all data points and hence may be affected by possible deviations from linear behaviour at both, high and low delamination rates. In a further step, the power law fits for each material are presented individually, this time including the non-linear (NL) and maximum or $5 \%(\mathrm{MAX} / 5 \%)$ initiation values from quasi-static testing of specimens of these laminates (again determined by the MCC method). From the four graphs in Figure 4, the following conclusions can be drawn: (1) Laminates C1 and G1 show a larger scatter in slopes than laminate C2, (2) laminate C2 clearly shows the lowest slope, while C1 and G1 seem to yield similar slopes, (3) laminates C1 and C2 show at least one fit with a distinctly different slope among the five data sets, and (4) for laminate $C 1$, all linear fits except one reach the average $M A X / 5 \%$ initiation value determined from quasi-static tests, whereas for C2 and G1 only one linear fit each exceeds the average NL value from the same tests. It can also be noted that the highest observed delamination rates $\mathrm{da} / \mathrm{dN}$ for all three laminates are on the order of about $5 \times 10^{-3} \mathrm{~mm} /$ cycle. If the values of the slopes from the different specimens are compared in a bar-plot (Figure 
5 ) it is evident that in spite of some scatter laminate C2 yields the lowest, C1 intermediate and G2 the highest values for the slopes. In this respect, the three laminates can clearly be distinguished.

However, a comparison of slopes is not sufficient for ranking the laminates with respect to their delamination resistance performance. A steep slope does indicate that a laminate may exhibit a significant increase in delamination-rate even for a small increment of the applied load (equivalent to $G_{\max }$ ) [8]. On the other hand, it is debatable whether a low slope will really be preferable since such a laminate may yield higher delamination-rates at relatively low applied loads. A linear fit that, for a given delamination-rate da/dN, corresponds to a "high" value of applied load $\mathrm{G}_{\max }$ may, in the end indicate a better delamination resistance than one for which the applied load is much smaller (at the same rate) independent of the slope. Taking an arbitrary delamination-rate of $10^{-5}$ $\mathrm{mm} /$ cycle and comparing the three laminates in Figure 6 yields lowest applied loads $G_{\max }$ of 69,111 , and $86 \mathrm{~J} / \mathrm{m}^{2}$ for $\mathrm{C} 1, \mathrm{C} 2$ and $\mathrm{G} 1$, respectively. This coincides with the relative ranking obtained from quasistatic mode I testing of the same laminates. Of course, if the same comparison were made at $10^{-7} \mathrm{~mm} /$ cycle and assuming that no thresholdlike effects would come into play at this rate, the ranking may look different with $\mathrm{C} 2$ yielding the lowest values (from extrapolation of the linear fits). These examples show that under certain assumptions, a relative ranking of the delamination resistance of different laminates can be established using the type of data analysis outlined above. A detailed statistical analysis of the results would in principle even yield confidence intervals for the values describing the ensemble of test data. 
It has, however, to be pointed out that before using any of these values for designing a composite structure, their validity will have to be firmly established (at least in an analysis of the full data set from the ASTM round robin) and in- and inter-laboratory scatter will have to be assessed in detail for determining suitable safety factors. As already noted above, steep slopes of the fatigue curves yield large uncertainties in predicted delamination growth rates for relatively small uncertainties in the applied load [8]. The same holds for large scatter in the slopes, if delamination growth rates are, e.g., used in design. Threshold values [6, 9] for mode I fatigue used in a "no-growth" design concept could be considered as an alternative, however, determination of such values may require long test duration, especially at low frequencies or large displacements. It might be advisable to change recommended specimen geometries from that of the quasi-static mode I tests (ASTM D5528 or ISO 15024) to less compliant beams for that. Further, as noted earlier [4], it is not clear whether such threshold values do exist or whether they appear due to limited experimental measurement resolution [10]. Evidence for effects caused by limited measurement resolution from selected ESIS round robin data will be presented and discussed below.

\subsection{ESIS Round Robin}

Analogous to the approach for data analysis of the ASTM round robin, all raw data from all participants (laboratories $A, B, C$; and $D$ ) obtained on two carbon FR-PMC (one thermoset epoxy and one thermoplast, i.e., PEEK) are compiled in Figure 7. In this case, the data for the thermoset and thermoplastic composites are readily distinguishable. At first sight, it is also clear that the thermoplastic shows a larger scatter than the thermoset laminate (neglecting one thermoset data set on the far left with a very 
steep slope). The full analysis of the data will be published elsewhere [11], but selected aspects will be discussed in this section. Performing the same linear fitting procedure described above and comparing the slopes of the linear fits for the thermoplastic AS4/PEEK laminate (Figure 8) shows that there is considerable in-laboratory as well as inter-laboratory scatter. Neglecting three extreme values of about $-0.9,63.5$ and 11.8 (laboratories $B, C$ and $D$, not shown) the average slope is roughly similar to that of laminate C2. Since all fits are located at applied loads $G_{\operatorname{Imax}}$ above 200 $\mathrm{J} / \mathrm{m}^{2}$, it is expected that the delamination resistance performance of the thermoplastic composite is superior to that of the thermoset.

A plot of machine load peak values and calculated delamination length is shown for one specimen of carbon FR-epoxy for laboratory A and B, respectively in Figure 9 . The noise in the load signal clearly differs for the two laboratories due to the different load cells used. This noise in the load signal is reflected in a corresponding noise in the delamination lengths calculated from the machine data. This finally results in significant scatter in the Paris plot for the specimen tested in laboratory $A$ at delaminationrates around $10^{-5} \mathrm{~mm} /$ cycle. The same composite tested in laboratory $B$ still yields a straight Paris plot at these rates. However, similar scatter to that found for laboratory $A$ at $10^{-5} \mathrm{~mm} /$ cycle is observed for specimens tested at laboratory $B$ for delamination-rates around $10^{-6} \mathrm{~mm} / \mathrm{cycle}$ and lower (Figure 10). This constitutes strong evidence that determination of Paris plots at low delamination-rates may be affected by measurement resolution, in particular by the choice of the load cell or calibrated load-cell range. At sufficiently low rates, an analogous and cumulative effect from variation in the displacement control of the test machines is expected to come into play as well. It is hypothesized that these effects may put 
limitations on the determination of mode I fatigue threshold values for composite laminates, even though this has not been attempted in the present round robin tests.

Close inspection of the calculated and visually determined delamination lengths as a function of cycle numbers (Figure 9) also indicates that stopping the test machines for visually reading delamination lengths may induce slight shifts in the load signals upon restarting the cyclic loads. This will ultimately also affect the accuracy of the determination of the Paris plot behaviour.

Since laminate type C2 from the ASTM round robin uses an epoxy type 5276-1 and material A from the ESIS round robin is using a similar epoxy (R5276), however with different carbon fiber types (G40-800 12k in C2 versus $\mathrm{G} 30-50012 \mathrm{k}$ ), the slopes of the linear fits for the two laminates can be compared (Figure 11). For the same delamination-rates, the fits for laminate C2 tend to be shifted to slightly higher values of applied load $\left(G_{I \max }\right)$. The data also seem to indicate a slightly higher slope for laminate C2 compared with laminate type A. This could be interpreted as indication of improved performance, but the data base for comparing averages and scatter is limited (5 specimens each tested at one single laboratory). It has to be noted that material $A$ has been stored for an extended period of time and hence may be affected by ageing. Nevertheless, it will be of interest to compare the full data set from all laboratories for each of the two materials, once the data are available.

\section{Conclusions}

The round robin data presented in this paper have shown the need for establishing structured data processing and analysis, if different laminates 
shall be compared with respect to their mode I cyclic fatigue delamination resistance behaviour. Due to the inherently large scatter, both inlaboratory as inter-laboratory, it may be difficult or virtually impossible to rank different laminates, if only raw data are used in the Paris plot. While the analysis methodology proposed in the present paper will provide a rough ranking, quite likely further detailed analyses will have to be performed for obtaining statistical confidence limits before using the data for design. Testing five specimens per laminate type may constitute a lower limit and more specimens may have to be tested for sufficient discrimination and statistical confidence. Testing at higher frequencies (up to $10 \mathrm{~Hz}$ ) may require stiffer specimens than those recommended by the quasi-static test procedures. The analysis has also indicated limitations arising from the resolution of machine load and displacement measurements which may affect determination of the so-called threshold behaviour of the laminates. Further research will be necessary to resolve these issues.

\section{Acknowledgments}

The support of Dr. Isabelle Paris (organizer of the ASTM D30.06 round robin) and of Dr. Mike Stuart (Cytec USA, for providing the additional specimens) as well as technical assistance with testing at Empa by Mr. Daniel Völki is gratefully acknowledged.

\section{References}

[1] P. Davies, B.R.K. Blackman, A.J. Brunner "Standard test methods for delamination resistance of composite materials: Current status", Appl. Comp. Mats. 5 (1998) 345-364. 
[2] T.E. Tay "Characterization and analysis of delamination fracture in composites: a review of developments from 1990 to 2001", Appl. Mech. Rev. 56 (2003) 1-23.

[3] A.J. Brunner, B.R.K. Blackman, P. Davies "A status report on delamination resistance testing of polymer-matrix composites", Eng. Fract. Mech. 75 (2008) 2779-2794.

[4] A.J. Brunner, N. Murphy, G. Pinter "Development of a standardized procedure for the characterization of interlaminar delamination propagation in advanced composites under fatigue mode I loading", Eng. Fract. Mech. 76 (2009) 2678-2689.

[5] A.J. Brunner, I. Paris, G. Pinter "Fatigue propagation test development for polymer-matrix fibre-reinforced laminates", Proc. $12^{\text {th }}$ Intl. Conf. on Fracture ICF-12, paper No. 00371 (2009), pp. 1-8.

[6] R.H. Martin, G.B. Murri "Characterization of mode I and mode II delamination growth and thresholds in AS4/PEEK composites", in: Composite Materials: Testing and Design, ASTM STP 1059 (S.P. Garbo, ed.), American Society for Testing and Materials (1990) 251270.

[7] A.J. Brunner, B.R.K. Blackman, P. Davies "Mode I Delamination" Chapter 4.1 in: Fracture Mechanics Testing Methods for Polymers, Adhesives and Composites (D.R. Moore, A. Pavan, J.G. Williams, eds.) Elsevier (2001) 271-305.

[8] L.E. Asp, A. Sjögren, E.S. Greenhalgh "Delamination growth and thresholds in a carbon/epoxy composite under fatigue loading", J. Compos. Technol. \& Res. 23 (2001) 55-68. 
[9] M. Hojo, S. Ochiai, K. Tanaka "Near-threshold propagation of delamination fatigue cracks in unidirectional CF/PEEK laminates in air and in water", Mater. Sci. Res. 1 (1995) 100-107.

[10] G. Allegri, M.I. Jones, M.R. Wisnom, S.R. Hallett "A new semiempirical model for stress ratio effect on mode II fatigue delamination growth", Compos. A: Appl. Sci. \& Manuf. A 42 (2011) 733-740.

[11] S. Stelzer, A.J. Brunner, A. Argüelles, N. Murphy, G. Pinter, Proceedings $6^{\text {th }}$ ESIS Conference (2011), in preparation.

\section{Figures}

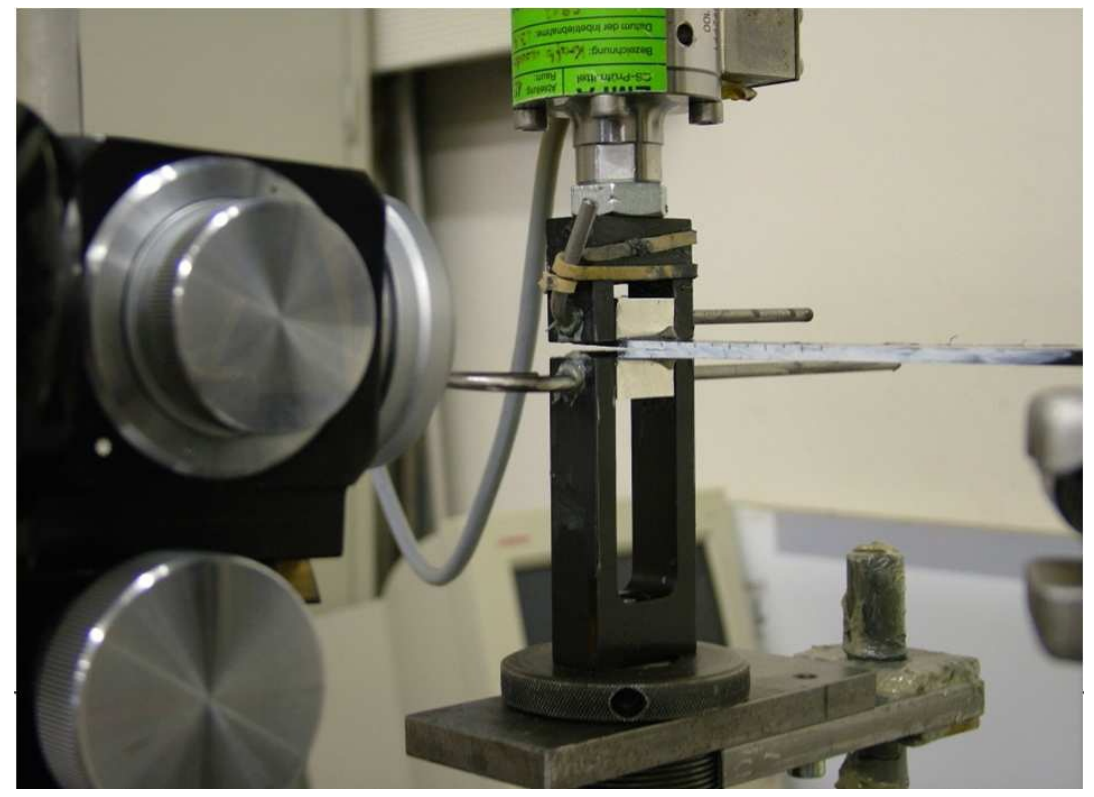

(Figure 1) 


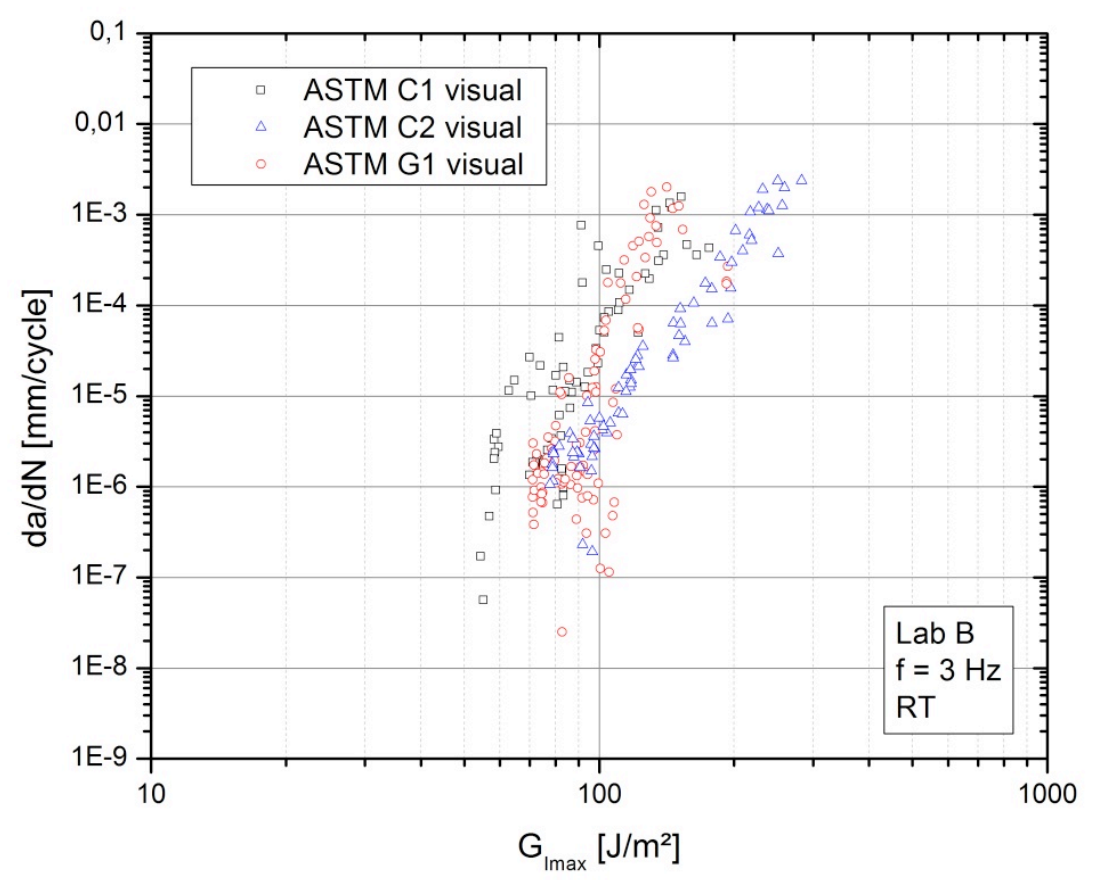

(Figure 2)

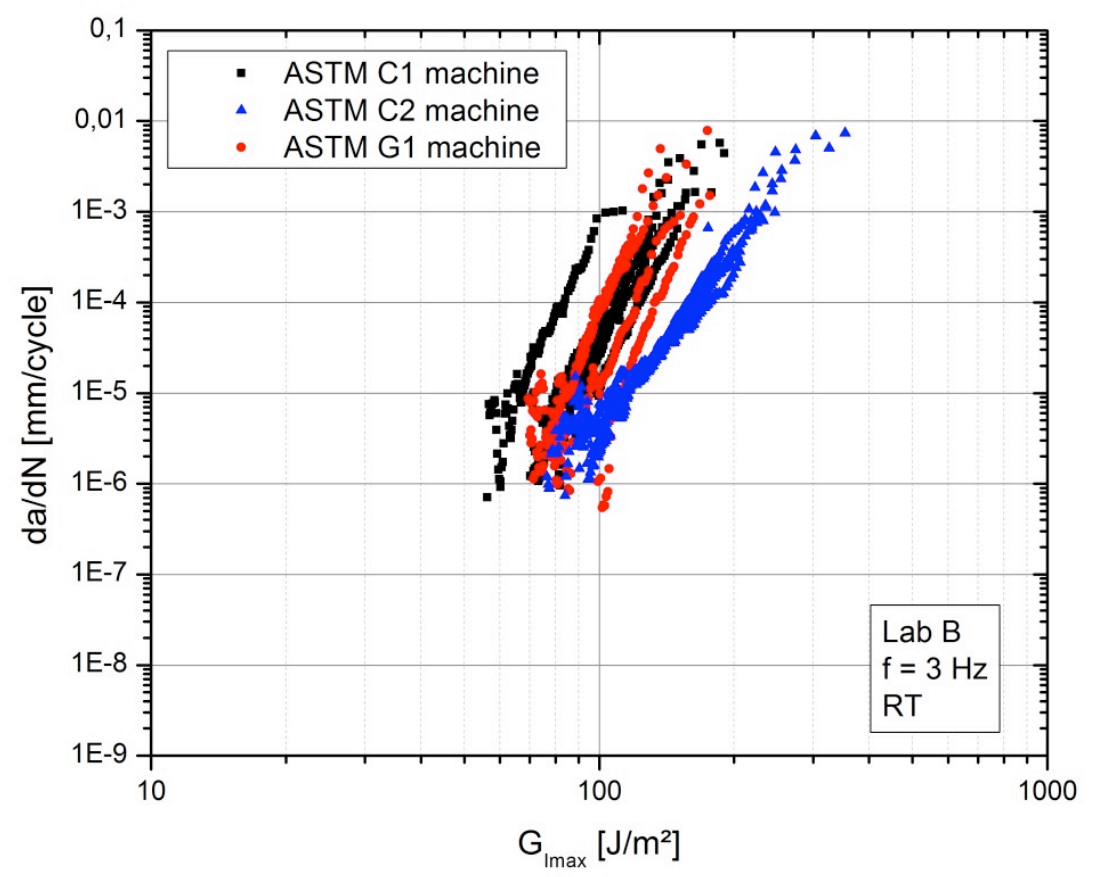

(Figure 3) 


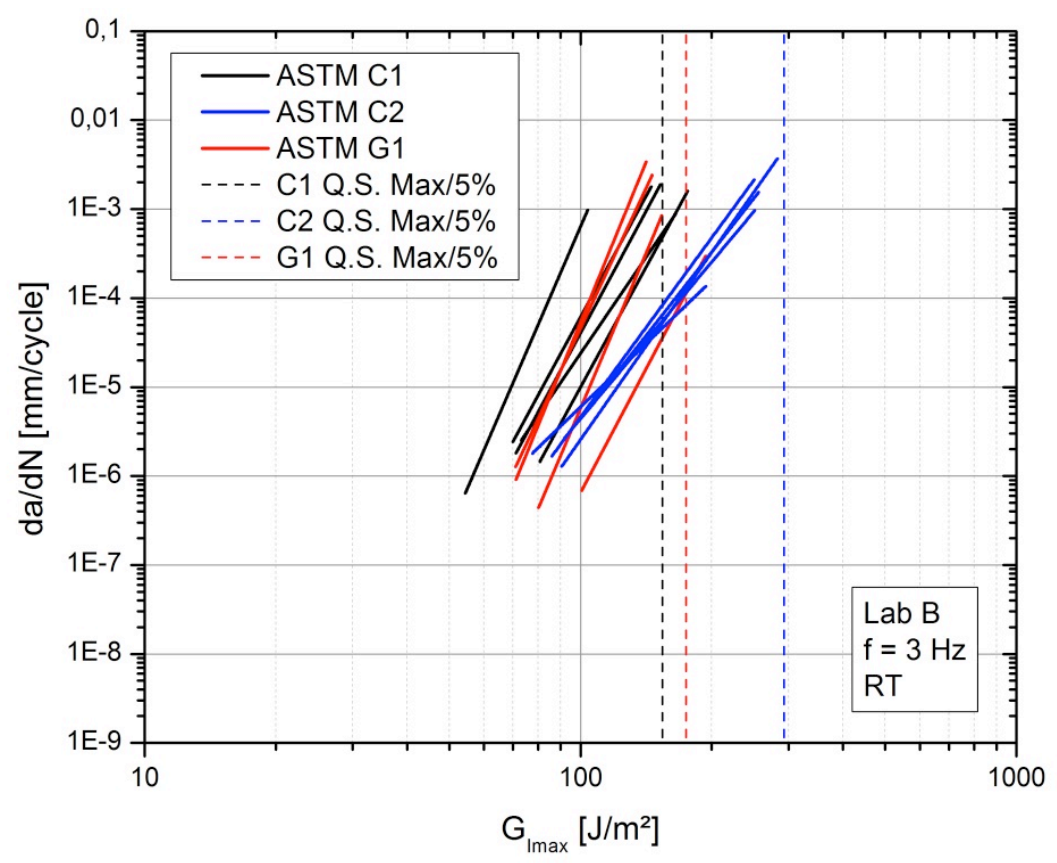

(Figure 4 a all fits)

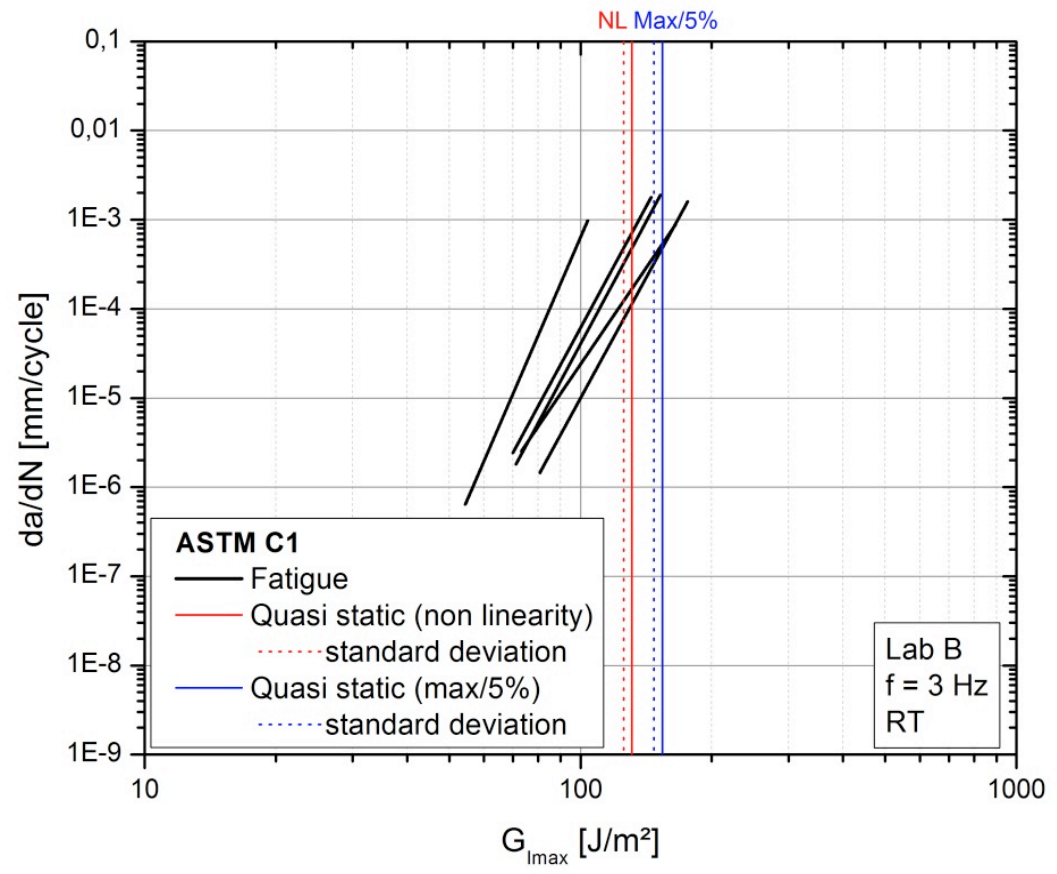

(Figure 4b fits C1) 


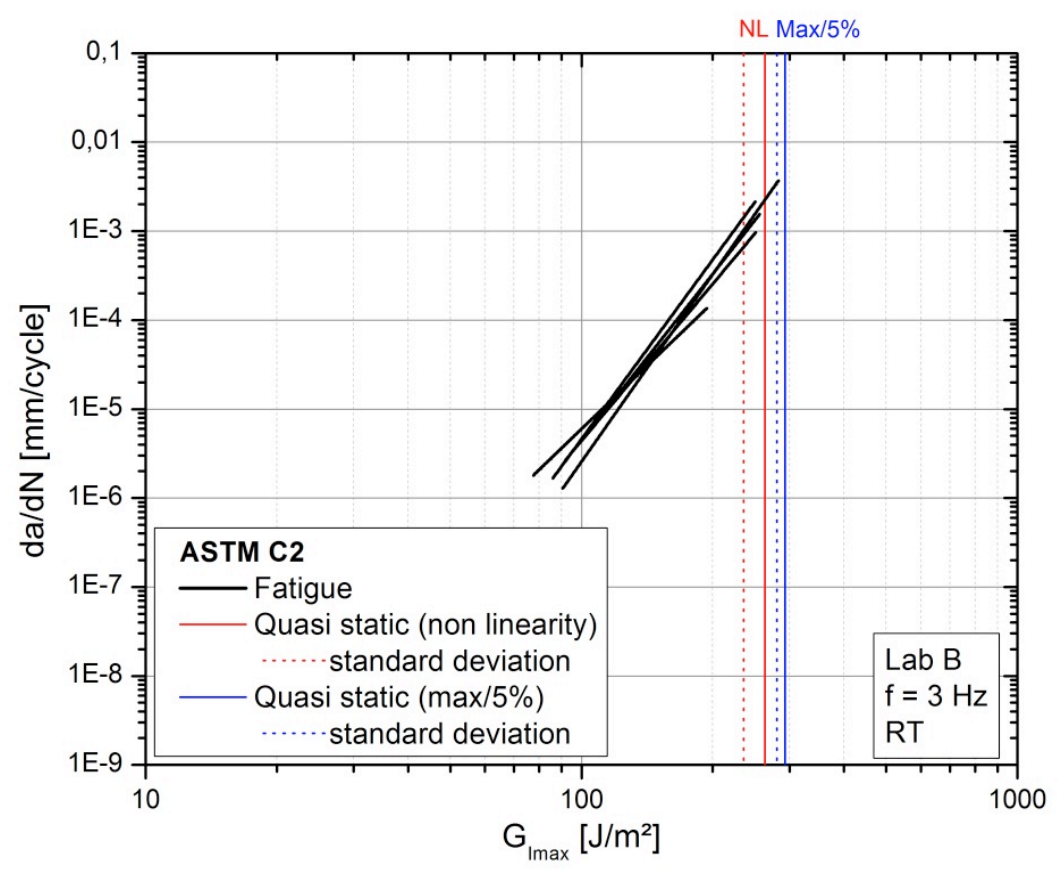

(Figure 4c fits C2)

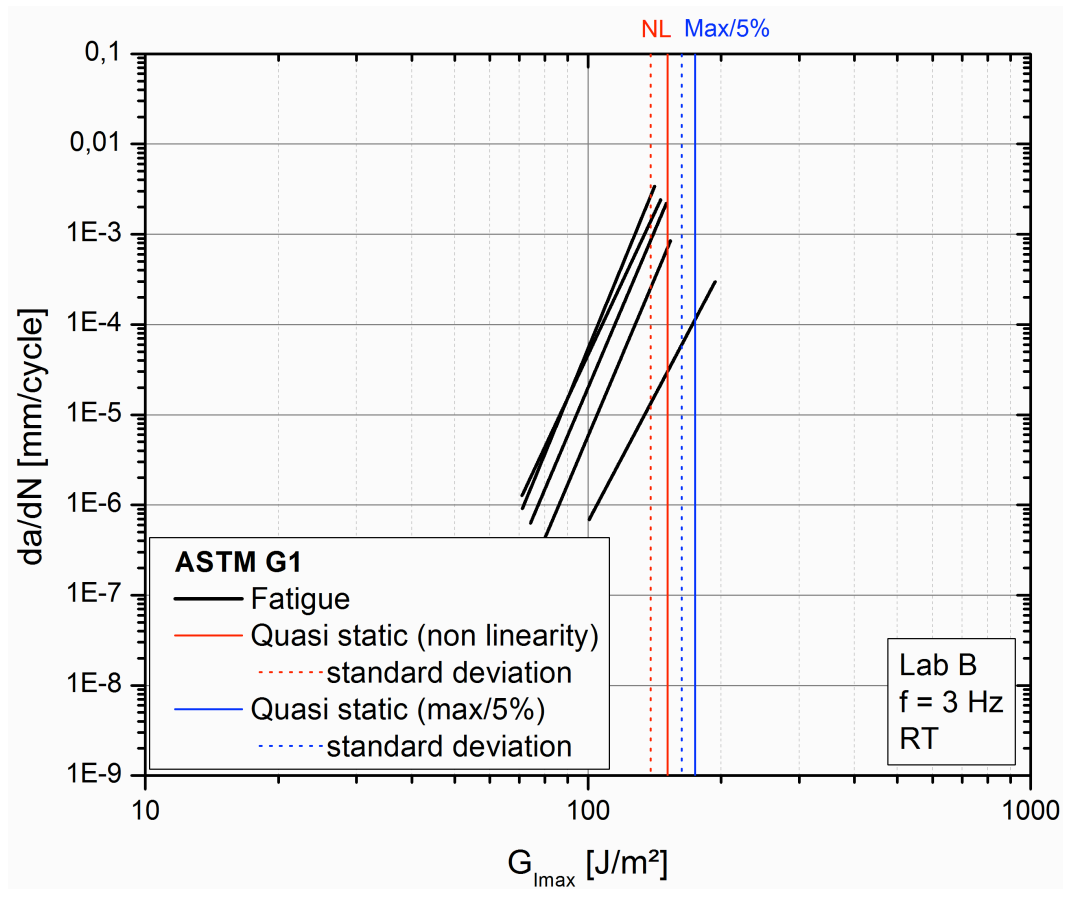

(Figure 4d fits G1) 


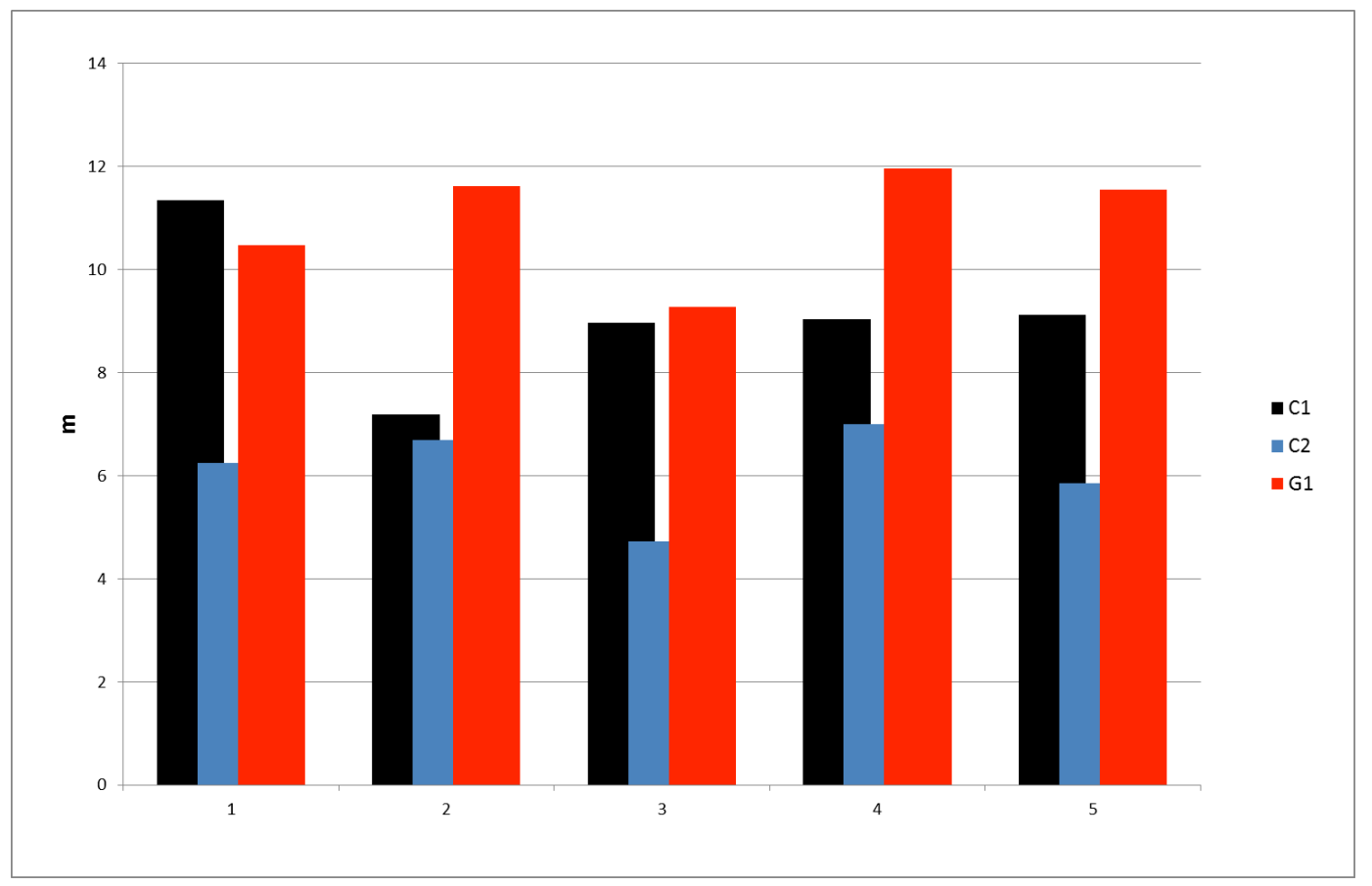

(Figure 5)

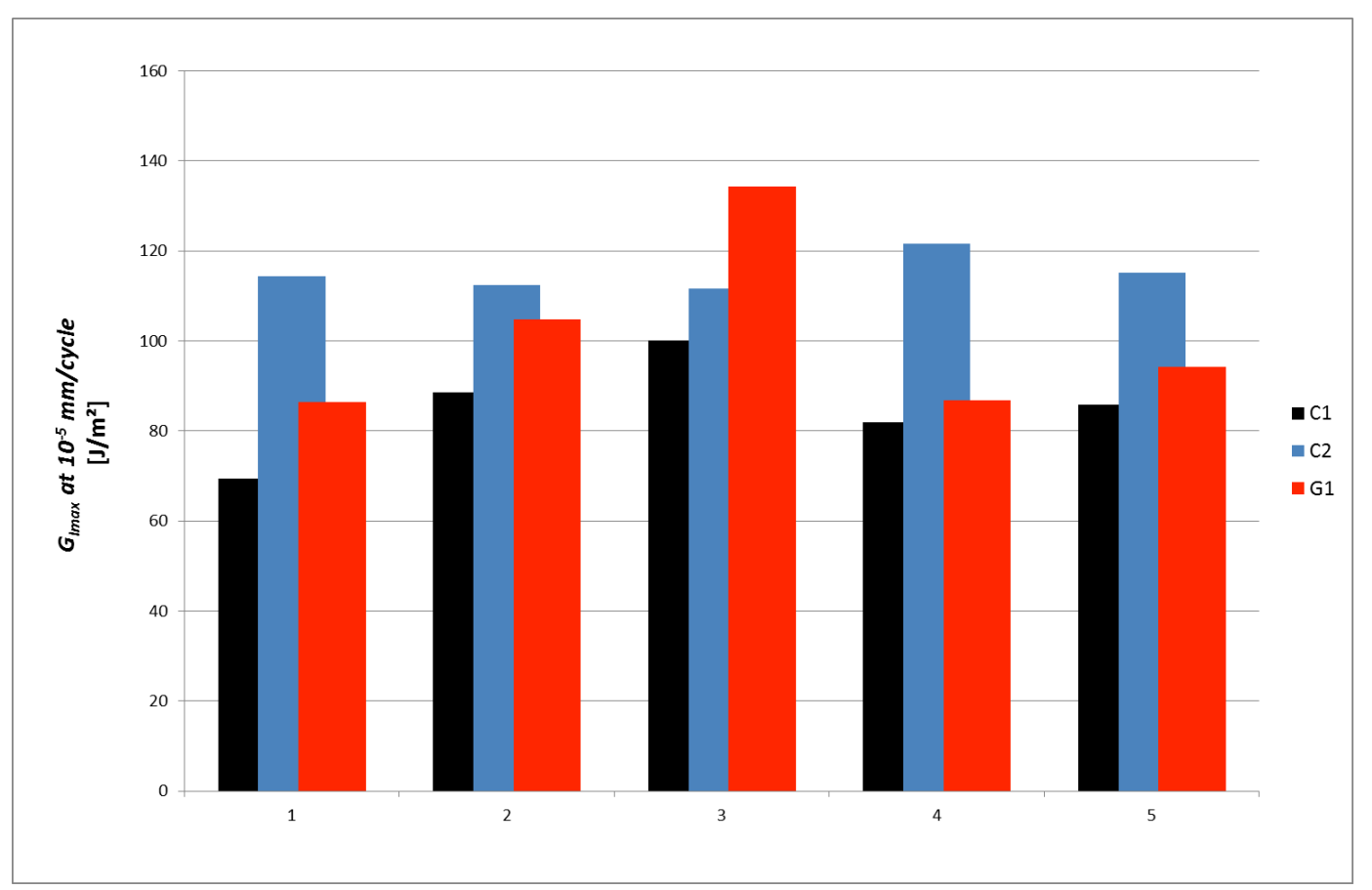

(Figure 6) 


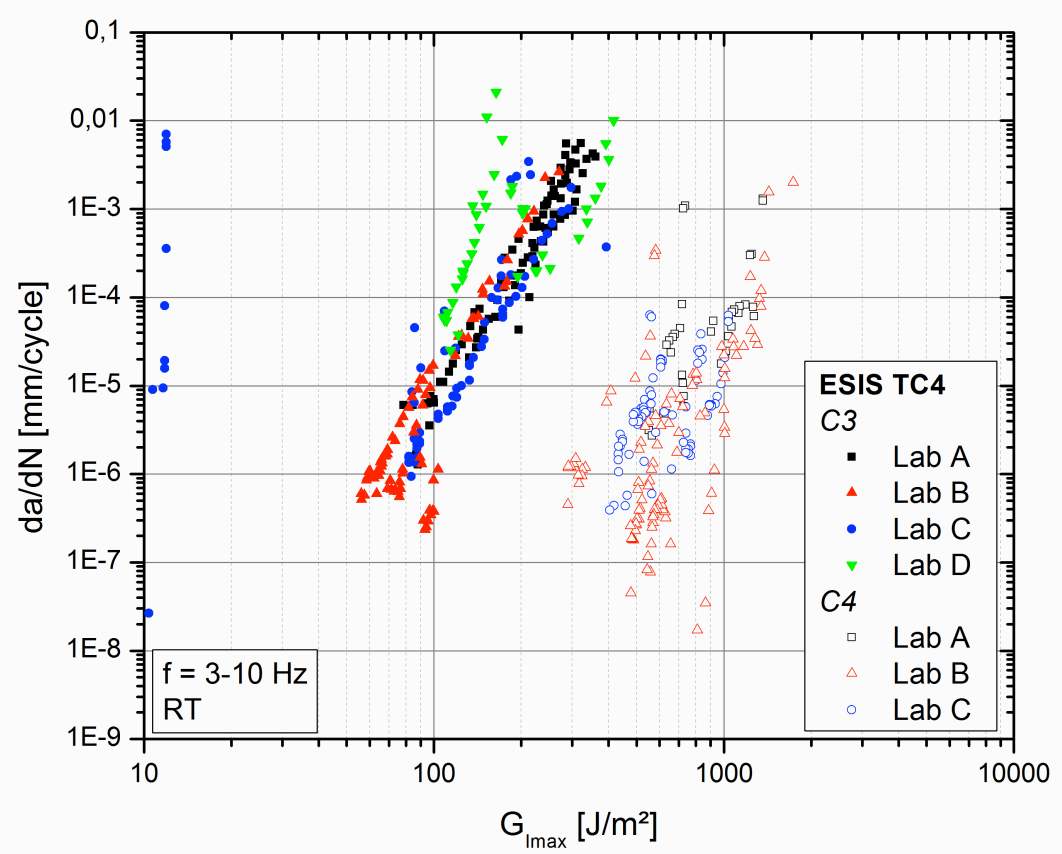

(Figure 7)

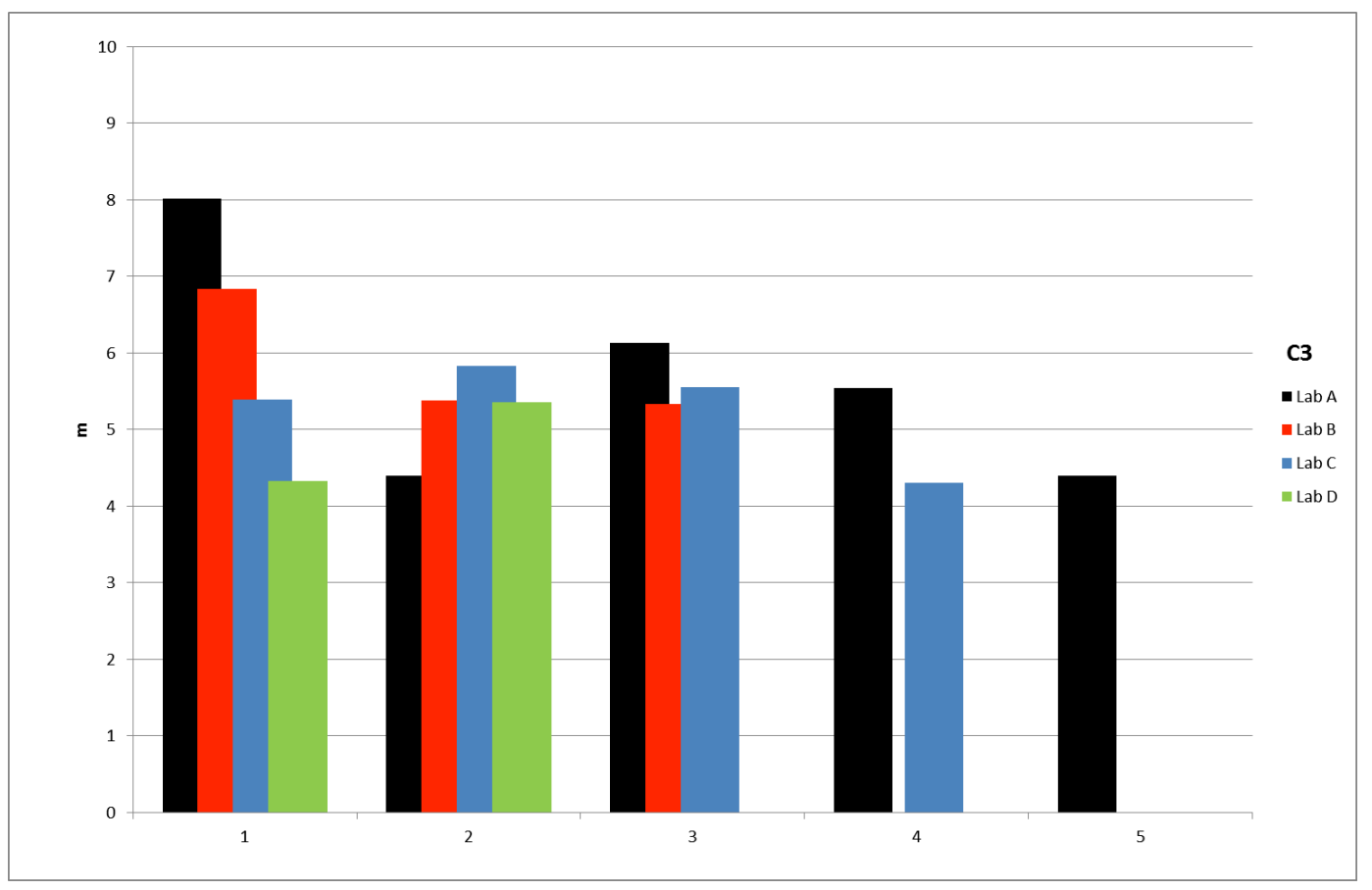

(Figure 8) 


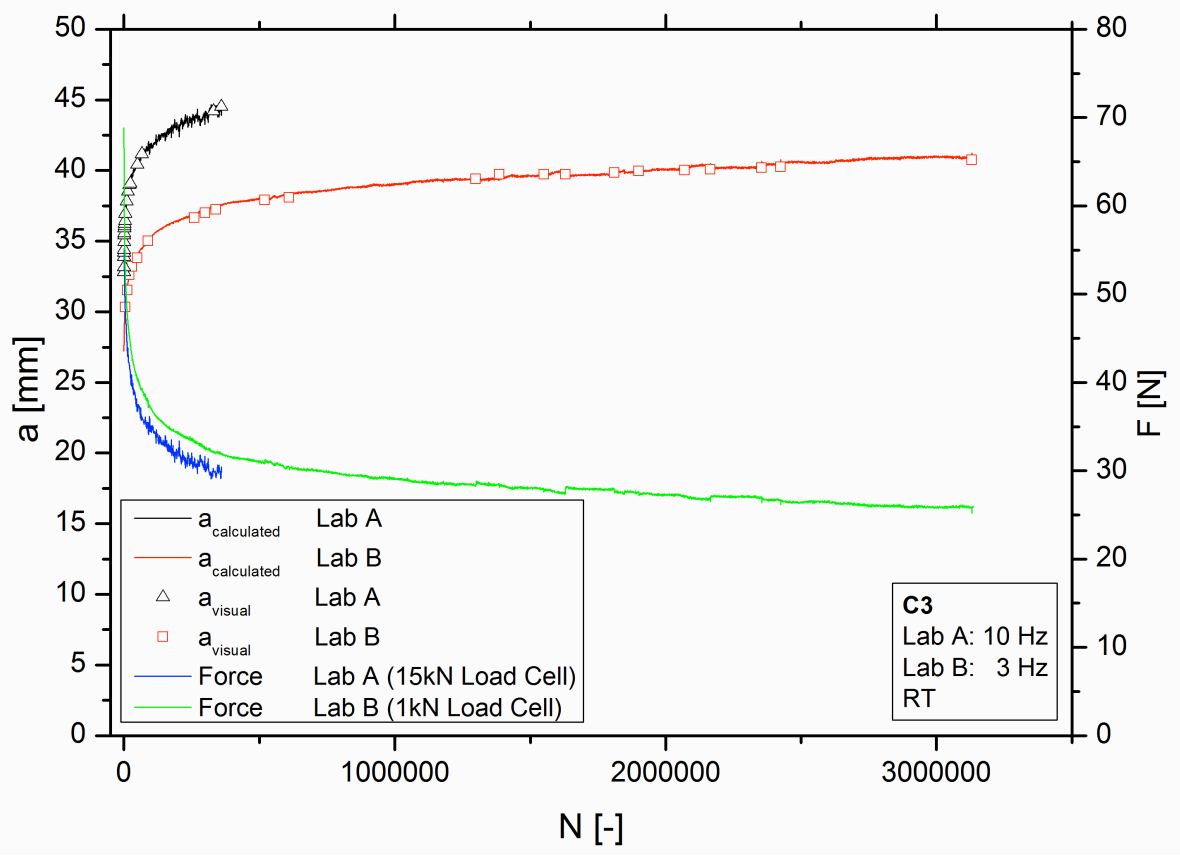

(Figure 9)

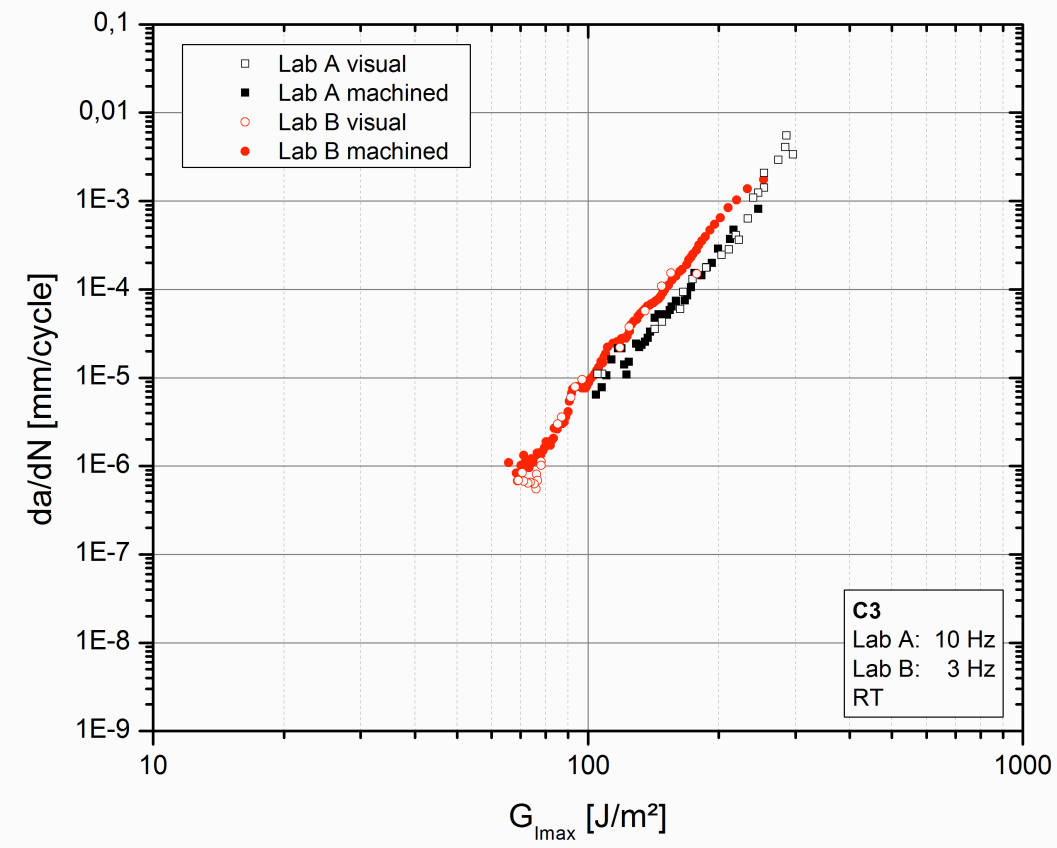

(Figure 10) 


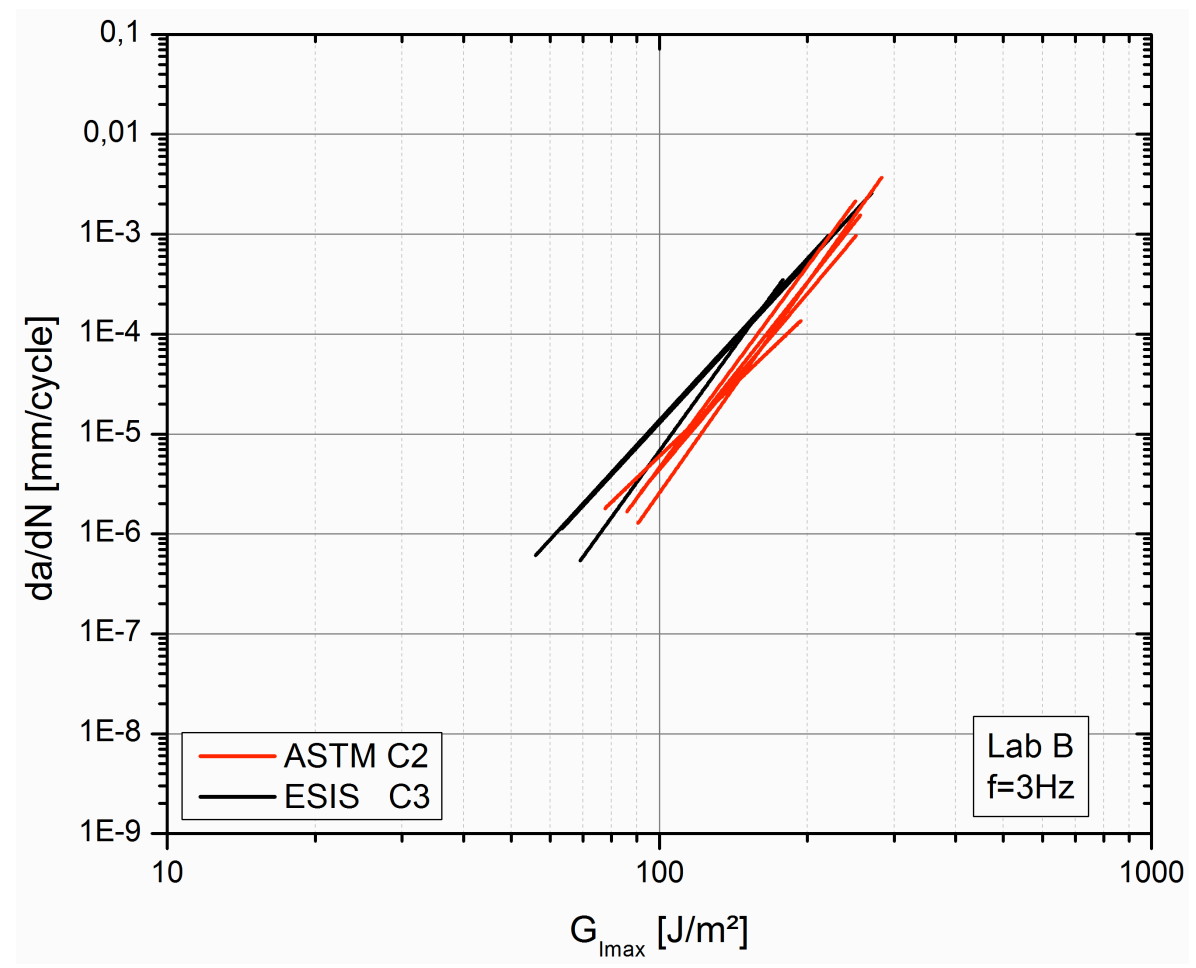

(Figure 11)

\section{Figure Captions}

Figure 1: $\quad$ DCB-specimen for mode I fatigue testing mounted in the fixture (laboratory B) without applied load; the travelling microscope for visually identifying the delamination tip is seen on the left.

Figure 2: Paris plot of all visual data recorded by laboratory B for three types of laminates used in the ASTM round robin, $G_{\max }$ has been evaluated by the modified compliance calibration (MCC) method.

Figure 3: $\quad$ Paris plot of the same data shown in Figure 1 but using delamination lengths back-calculated from machine compliance instead of visually determined delamination lengths. The number of data points has been reduced by requiring a minimum delamination length of 50 micrometer between each data point. 
Figure 4: $\quad$ Paris plots of the fatigue data represented by linear fits for each specimen, (a) for all three laminates, (b) for laminate type $\mathrm{C} 1$, (c) for laminate type $\mathrm{C} 2$, and (d) for laminate type G1. The average non-linear and maximum or $5 \%$ initiation values determined from quasi-static tests are shown as thick dotted lines with thin dotted lines indicating the lower standard deviation (averages and standard deviations from testing 5 separate specimens per laminate).

Figure 5: $\quad$ Comparison of the slopes $(\mathrm{m})$ obtained from linear fits of the Paris plots for each specimen.

Figure 6: Comparison of the $\mathrm{G}_{\max }$ values at $10^{-5} \mathrm{~mm} /$ cycle obtained from linear fits of the Paris plots for each specimen.

Figure 7: $\quad$ Paris plot of all visual data recorded by laboratories $A, B, C$ and $D$ for two types of laminates used in the ESIS round robin, $G_{I \max }$ has been evaluated by the modified compliance calibration (MCC) method

Figure 8: $\quad$ Comparison of the slopes $(\mathrm{m})$ obtained from linear fits of the Paris plots for each specimen from the G30-500/R5276 laminate.

Figure 9: $\quad$ Machine load and calculated delamination length versus cycle number (laboratory A and B) for the carbon FR-PMC. Visually determined delamination lengths (machine stopped) are also indicated (see text for details).

Figure 10: Paris plot for one specimen of carbon FR-PMC for laboratory $A$ and $B$, respectively 
Figure 11: Comparison of Paris plots for laminate types C2 and C3 using a similar epoxy matrix (all test data from laboratory B).

\section{Tables}

Table 1: Materials used in the ASTM D30.06 round robin

\begin{tabular}{l|l|l|l}
\hline & C1 & C2 & G1 \\
\hline Fiber & Carbon, IM7 & Carbon, G40-800 12k & Glass, S2 \\
Matrix resin & Epoxy, 977-3 & Epoxy, 5276-1 & Epoxy, 5216 \\
Lay-up & {$[0]_{26}$} & {$[0]_{26}$} & {$[0]_{18}$} \\
Thickness $(\mathrm{mm})$ & $3.5($ nominal 3.5) & 3.4 (nominal 3.7) & 4.1 (nominal 4.0) \\
\hline
\end{tabular}

Table 2: Materials used in the ESIS TC4 round robin

\begin{tabular}{l|l|l}
\hline & C3 & C4 \\
\hline Fiber & Carbon, G30-500 12k & Carbon, AS4 \\
Matrix resin & Epoxy, Rigidite 5276 & PEEK \\
Lay-up & {$[0]_{24}$} & {$[0]_{24}$} \\
Thickness (mm) & 4.0 & 3.0 \\
\hline
\end{tabular}

Table 3: Quasi-static Mode I averages from the ASTM D30.06 round robin (Laboratory B, 5 specimens each)

\begin{tabular}{l|c|c|c}
\hline & $\mathrm{C} 1$ & $\mathrm{C} 2$ & $\mathrm{G} 1$ \\
\hline Initiation $\mathrm{G}_{\mathrm{IC}}(\mathrm{NL}) \pm$ standard & $120 \pm 9.7$ & $253 \pm 23.8$ & $147 \pm 11.8$ \\
deviation $\left[\mathrm{J} / \mathrm{m}^{2}\right]$ & & & \\
Initiation $\mathrm{G}_{\mathrm{IC}}(\mathrm{MAX} / 5 \%) \pm$ standard & $145 \pm 12.1$ & $290 \pm 11.8$ & $172 \pm 11.9$ \\
deviation $\left[\mathrm{J} / \mathrm{m}^{2}\right]$ & & & \\
Average Propagation \pm standard & $174 \pm 16.5$ & $337 \pm 27.1$ & $432 \pm 27.7$ \\
deviation $\left[\mathrm{J} / \mathrm{m}^{2}\right]$ & & &
\end{tabular}




\begin{tabular}{|c|c|c|c|}
\hline $\begin{array}{l}\text { Maximum Propagation } \pm \text { standard } \\
\text { deviation }\left[\mathrm{J} / \mathrm{m}^{2}\right]\end{array}$ & $184 \pm 17.2$ & $357 \pm 34.2$ & $574 \pm 26.9$ \\
\hline $\begin{array}{l}\text { Back-calculated E-modulus } \pm \\
\text { standard deviation [GPa] }\end{array}$ & $122 \pm 5.8$ & $142 \pm 12.5$ & $59 \pm 13.3$ \\
\hline
\end{tabular}

\section{Table Captions}

Table 1: $\quad$ Materials used in the ASTM D30.06 round robin

Table 2: $\quad$ Materials used in the ESIS TC4 round robin

Table 3: $\quad$ Quasi-static Mode I averages from the ASTM D30.06 round robin (Laboratory $\mathrm{B}, 5$ specimens each) 